\title{
La pugna entre el shareholder primacy model y la stakeholder theory en la doctrina y práctica anglosajona. Estado de la cuestión
}

\author{
Iñigo Zavala Ortiz de la Torre \\ Universidad de Deusto
}

Sumario: I. Introducción. II. Marco general teórico. III. The shareho/der value o shareholder primacy theory. IV. The stakeholder theory. V. Estado práctico de la cuestión en EE.UU. y el Reino Unido. VI. Breve análisis comparado de los códigos de gobierno corporativo. VII. Conclusión. VIII. Bibliografía.

Resumen: Existe una pugna entre los defensores de que los accionistas sean la referencia, a la que la dirección de la empresa tiene que mirar cuando adopta sus decisiones; frente a los que creen que, junto a estos se deben tomar en cuenta los intereses de otros stakeholders como son los trabajadores, los acreedores, los proveedores y los clientes. Si bien la doctrina, e incluso las posibilidades legislativas, avalan la segunda postura en los países anglosajones; tanto la práctica, como el análisis de los principales Códigos de Buen Gobierno, nos muestran que en realidad sigue vigente la primera. ¿Porqué?

Palabras clave: Accionistas, stakeholders, dirección de la sociedad, doctrina anglosajona, constituency statutes, enlightened shareholder value, códigos de buen gobierno corporativos.

Abstract: There exists a struggle between the activist of the Shareholder Primacy Model, and those who support the Stakeholder Theory (in the interest of the shareholders, employees, customers, creditors and suppliers). Although the scholars and the legislations are prone to the second theory, the reality and the analysis of the Corporate Governance Codes, shows us that the former one is still in the victorious. Why?

Key words: Shareholders, stakeholders, management, anglo-saxons scholars, constituency Statutes, enlightened shareholder value, corporate governance codes. 


\section{Introducción}

Se ha escrito mucho sobre la crisis económico-financiera que ha asolado el «mundo civilizado» en general, y a nuestro país en particular. Han sido muchas las causas señaladas. Existe un consenso amplísimo, en mencionar como una de las principales, la visión corto placista del negocio como consecuencia de la avidez insaciable de dividendos por parte de los accionistas. Todo ello precipitado, o amplificado, por una política retributiva de los grandes directivos que tenía como eje central la obtención de suculentos bonus o stock options, ligadas al incremento de los beneficios y/o del valor de la acción de la compañía en el corto plazo. El resultado, todos los conocemos. Los mayores damnificados ... ¿Los accionistas? No. Ellos ya recibieron durante los primeros siete años de este siglo — vía dividendos - una retribución desproporcionada y vampírica (para con las sociedades) como contraprestación a su inversión en la compañía. Los verdaderos damnificados han sido los otros grupos sociales, también interesados en el éxito de la sociedad, y que ni en los años dorados recibieron «su» parte en la forzada generación de beneficios, ni luego, en los años de crisis, y como es obvio, pudieron percibir nada en donde «no quedaba nada».

Son innumerables los artículos, libros, conferencias y jornadas que durante los últimos años han demandado, de forma casi unánime, un cambio en la forma de entender la sociedad, no solo en sus relaciones con el exterior - el medio ambiente, la defensa de los derechos humanos...- si no también en el aspecto interno, es decir, en lo que afecta a su fin u objetivo. Efectivamente, la doctrina internacional, la clase política ${ }^{1}$ y las Instituciones Religiosas ${ }^{2}$ más representativas, claman por

1 El Presidente Obama afirma que la riqueza de los ricos, no se debe solo a sus propios esfuerzos, si no también a la participación del Estado y otros interesados. Ver en http://www. dailymail.co.uk/news/article-2174160/Obama-says-wealthy-ARENTresponsible-uccess.html

2 Para la Iglesia Católica, la empresa/sociedad mercantil «... debe caracterizarse por la capacidad de servir al bien común de la sociedad mediante la producción de bienes y servicios útiles. En esta producción de bienes y servicios con una lógica de eficiencia y de satisfacción de los intereses de los diversos sujetos implicados, la empresa crea riqueza para toda la sociedad: no sólo para los propietarios, sino también para los demás sujetos interesados en su actividad. Además de esta función típicamente económica, la sociedad desempeña también una función social, creando oportunidades de encuentro, de colaboración, de valoración de las personas implicadas. En la empresa, por tanto, la dimensión económica es condición para el logro de objetivos no sólo económicos, sino también sociales y morales, que deben perseguirse conjuntamente. El objetivo de la empresa se debe llevar a cabo en términos y con criterios económicos, pero sin descuidar los valores auténticos que permiten el desarrollo concreto de la persona y la sociedad... 
una modificación del objetivo de la sociedad, para adecuarlo a una concepción más humana y moralmente defendible.

Sin embargo, ¿dónde nos encontramos? A través del presente artículo queremos dar una visión, de cuál es el estado de la cuestión, primero a nivel doctrinal, y luego en la práctica societaria. Dada la inabarcabilidad de la tarea, para un trabajo tan modesto como el que nos ocupa, centraremos el mismo, al menos en lo que al ámbito doctrinal se refiere en el mundo anglosajón. Y ello por dos motivos. El primero por que entre los Estados Unidos y el Reino Unido, controlan más de la mitad del mercado financiero mundial, con lo que sus instituciones, y especialmente sus sociedades, son objeto de una permanente atención, con el objetivo de poder ofrecer a los inversores de todo el mundo, vehículos ágiles y seguros con los que, y en los que realizar sus inversiones.

Efectivamente, con la globalización, nos encontramos ante un mercado mundial altamente competitivo, en el que para mantener el mencionado liderazgo estos países han desarrollado unas instituciones, un marco regulatorio, y una legislación societaria ${ }^{3}$, que les hace ser no solo receptores de inversores; si no también exportadores de conceptos, ideas y de un know-how económico financiero que, nos guste o no, está impregnando los sistemas del resto de países del planeta.

En segundo lugar, porque cuentan con la doctrina más relevante, con el mayor número de publicaciones editadas, así como con la perspectiva que da el tratamiento legislativo otorgado al problema desde hace ya casi 50 años.

Los componentes de la empresa deben de ser conscientes de que la comunidad en que trabajan representa un bien para todos y no una estructura que permite satisfacer exclusivamente los intereses personales de algunos... Es indispensable que, en la sociedad, la legítima búsqueda del beneficio se armonice con la irrenunciable tutela de la dignidad de las personas que a titulo diverso trabajan en la misma. Es indispensable que, dentro de la empresa, la legítima búsqueda del beneficio se armonice con la irrenunciable tutela de la dignidad de las personas que a título diverso trabajan en la misma. Estas dos exigencias no se oponen en absoluto, ya que por una parte, no sería realista pensar que el futuro de la empresa está asegurado sin la producción de bienes y servicios y sin conseguir beneficios que sean el fruto de la actividad económica desarrollada; por otra parte, permitiendo el crecimiento de la persona que trabaja, se favorece una mayor productividad y eficacia del trabajo mismo. La empresa debe de ser una comunidad solidaria, no encerrada en los intereses corporativos, tender a una ecología social del trabajo, y contribuir al bien común, incluida la salva guardia del ambiente natural.» Ver, en «Compendio de la Doctrina Social de la Iglesia». Consejo Pontificio «Justicia y Paz». Ed: Biblioteca de Autores Cristianos. 2012.

3 Charny, D., "Competition among Jurisdictions in Formulating Corporate Law Rules; An American Perspective on the "Race to the Bottom" in European Communities», en Harvard International Law Journal, vol. 32 de 1991, p. 423. Romano, R., "The genious of American Corporate Law». Ed. AEl Press. Washington, U.S.A. 1993, p. 129. 
De esta forma, el estudio del Derecho de sociedades americano, se ha vuelto indispensable para los comparativistas y los reformadores del derecho. Su influencia sobre el derecho europeo de sociedades y del mercado financiero, es incontestable, dejándose sentir, asimismo, en las demás ramas jurídicas con relevancia económica ${ }^{4}$.

Bien es cierto, y esto hay que repetirlo, que el mercado norteamericano tiene unas características propias ${ }^{5}$ que nos harán, por supuesto, matizar, adecuar y reamoldar a nuestra realidad sus normas.

Además y por ser, precisamente las actoras (para lo bueno y lo malo) de todo lo dicho hasta ahora, focalizaremos nuestro trabajo en las sociedades cotizadas. Efectivamente, la forma jurídica utilizada para dar cobertura a las empresas cuyas acciones cotizan en los diferentes mercados, se ha visto sometida a un grado de acercamiento y unificación tal, que permite a operadores jurídicos y económicos de distintos países ser capaces de entender y comparar las distintas exigencias requeridas por cada ordenamiento jurídico. Así es, la forma jurídica elegida, es decir, la sociedad mercantil con responsabilidad limitada de los socios a la aportación social (Corporation, Societe, Societta, Agchung), tiene en todas las legislaciones características comunes y básicas, pudiéndoseles aplicar a todas ellas las reflexiones que en el presente trabajo realizamos.

Efectivamente, siguiendo a la doctrina más relevante 6 , podemos determinar que en las sociedades de los principales países desarrollados, son muchas más las características comunes, que las divergencias. Y así, tanto la 1. personalidad jurídica, 2. la responsabilidad limitada de sus socios, 3. la transmisibilidad de las acciones 4 . la delegación de las facultades de administrar la sociedad, en una dirección colegiada o consejo de administración, y 5 . la propiedad de la misma por sus accionistas; son características que aparecen en todas ellas. Estos rasgos distintivos han sido configurados de acuerdo con las necesidades económicas de la moderna empresa, y esto hace que, de manera permanente, todas ellas se encuentren recogidas en los elementos que conforman a las sociedades cotizadas que desarrollan las grandes aventuras empresariales de nuestro tiempo. Por lo tanto, los constituyen-

4 Hopt, K.J., Estudios de Derecho de Sociedades y del Mercado de valores. Ed. Marcial Pons. Madrid. 2010, pp. 270 y 271. Sobre la preeminencia de la doctrina norteamericana.

5 Hopt, K.L., «Estudios de Derecho de Sociedades...», op. cit., p. 53. Las características propias de cada sistema normativo o "path dependence».

6 Kraakman, R. et al., The Anatomy of Corporate Law. A comparative and functional approach, 2. ${ }^{a}$ edición. Oxford. Oxford University Press. 2009, op. cit., pp. 6 y ss. En donde los autores recogen enuncian y comentan las cinco características. 
tes de una sociedad que tenga por objeto el desarrollo de una gran empresa, y cuya forma de financiación parcial o total, se realice a través del ahorro público concretado en el mercado de capitales, tendrán obligatoriamente que «crear» una sociedad que contenga, al menos las mencionadas características ${ }^{7}$.

Las Sociedades han sido y son las instituciones económicas que dominan nuestro mundo. Son las estructuras más utilizadas para encauzar cualquier actividad empresarial ${ }^{8}$. En el año 2000 el «Institute for Policy Studies», publico un estudio, en el que se mostraba que, entre las 100 mayores entidades económicas del planeta, 51 eran Sociedades y 49 Estados. Entre las primeras, existían 22 compañías cuya capitalización bursátil era mayor que el producto Interior Bruto de 22 países 9 . Estas grandes compañías, toman decisiones que, aún adoptadas en el ámbito privado de su actividad, tienen transcendencia pública. Esta innegable influencia en nuestra sociedad, ha llevado a muchos autores a negarles la cualidad de entidades de derecho privado; para asegurar que realmente son instituciones de derecho público, con obligaciones frente a la sociedad. ${ }^{10}$

Pero dicho esto, es necesario, tal y como Michael Jensen dijo que «Toda organización que quiera cumplir con un objetivo, tiene que contestar a la siguiente pregunta: ¿Qué objetivo estamos tratando de cumplir?» ${ }^{11}$. Intentaremos resumir, en este artículo, las teorías más importante que, a día de hoy, y en la doctrina anglosajona, quieren dar contestación a esa pregunta. Para ello realizaremos una breve revisión del marco actual existente en EE.UU. y el Reino Unido en el apartado II de este trabajo; para seguidamente comentar la Shareholders Primacy (SP), en el apartado III; la Stakeholder Theory (STKT) en el IV; cuál es la realidad práctica en ambos países, en el V; un breve análisis comparado de Códigos de Buen Gobierno, a los efectos del presente trabajo, en el $\mathrm{Vl}$; y finalmente unas Conclusiones, en el VII.

7 Ver Easterbrook, H.F y Fischel, D.R., The economic structure of Corporate Law. Ed: Harvard University Press. Harvard. 1991, p. 4.

8 Couwenberg, O., "Corporated Arquitecture and Limited Liability». en Review of Law and Economics. 2008, vol. 4. pp. 621 a la 622.

9 Institute for Policy Studies studio realizado por Anderson, S. y Cavanagh, J., Disponible en http://www.ips-dc.org/downloads/Top_200.pdf. Última entrada, 20 de enero de 2013

10 Branson, D., "The Death of Contractarianism and the Vindication of Structure and Authority in Corporate Governance and Corporate Law», en Mitchell, L., Progressive Corporate Law, Boulder, Ed: Westv iewPress, 1995, p. 93.

11 Jensen, M., «Value Maximisation, Stakeholder Theory, and the Corporate Objetice Function», en European Financial Management, vol. 7 de 2001, p. 149. 


\section{Marco general teórico actual}

Si bien es cierto que este problema ha sido abordado en miles de artículos y trabajos doctrinales (algún autor, gráficamente ha dicho que el asunto ha sido debatido "ad nauseam» ${ }^{12}$ ), lo cierto es que ha día de hoy, el debate, aun reducido a la pugna entre la Shareholder Primacy y a la Stakeholder Theory, dista mucho de haber sido cerrado. Realmente el quid de la cuestión es determinar en beneficio de quien debe, la dirección y el Consejo de la compañía, gestionar la misma. Si la dirección debe tener en cuenta, preferentemente los intereses de los accionistas, estaremos en presencia del SP model, y si, por el contrario la dirección (o management ${ }^{13}$ ) tiene que tener en cuenta los intereses de todos los Stakeholders, nos encontraremos ante la STKT.

Antes de entrar en el análisis a fondo de estas dos principales teorías, será necesario dar unas pinceladas, a modo de recordatorio, sobre cuales son las bases sobre las que, la doctrina anglosajona más influyente, construye las diversas proposiciones que tratan de explicar su concepción de las sociedades en general, y de las capitalistas en particular. Lo haremos mencionando las teorías derivadas de los estudios de la Escuela Económica del Derecho, para luego abordar las denominadas «Comunitarias» O «Progresivas».

Las primeras, han tenido un éxito total en Estados Unidos a raíz de los estudios de la llamada Escuela de Chicago en los años 70. Esta posición doctrinal, entiende que las sociedades son entidades privadas, producto de la libre iniciativa de los ciudadanos, y nunca instituciones públicas. En este caso, existe una mayor influencia y aportación de la ciencia económica que de la del Derecho. Esta escuela del análisis económico del derecho ha dado lugar a la creación de cuatro posiciones (sub-teorías) diferentes. Una (y la más importante) es la denominada «contractualista». Según sus defensores, la sociedad es un «nexo de contratos» ${ }^{14}$; más explícitamente otro de sus apóstoles, Robert Clark ${ }^{15}$ señala que

12 Butler, H.N. y McChesney, F.S., "Why they give at the office: shareholder Welfare and Corporate Philantrophy in the contractual Theory of the Corporation», en Cornell Law Review, vol. 84 de 1999, p. 1195.

13 Término que, en este trabajo, utilizaremos de forma indistinta con el de Directivo; en contraposición con la traducción del término inglés "Director» a la que asignamos la traducción como «Consejero».

14 Easterbrook, F. y Fishel, D., «The Corporate Contract», en Columbia Law Review, vol. 89 de 1989, p. 1426.

15 Clark, R., Corporate Law. Chicago. Ed: Aspen Publishers. 1986. 
The corporate contract consists of the terms of a corporation's charter and the corporate law the firm selects by virtue of incorporating in a particular state. The contractarian theory of the firm also implies a theory of the role of corporate law: corporate law should merely provide a set of default rules that managers may adopt on behalf of their firms, while leaving managers free to customize their companies' charters with legally enforceable rights and obligations.

El pensamiento económico analiza la sociedad, como a un tipo social sin más, como una mera ficción; pero obviando una parte fundamental de la misma como es la irrupción en el tráfico mercantil, de una nueva sociedad, con personalidad jurídica propia y distinta de la de sus socios. Con esta teoría, la sociedad es desestructurada, al ser conceptualizada como un conjunto de complejos contratos privados, bien sean expresos o tácitos, que dan forma a un gran número de relaciones jurídicas a las que se llega entre las distintas partes que —voluntariamente - se relacionan con la compañía y sus diversos stakeholders ${ }^{16}$. Existirán, por lo tanto contratos entre los accionistas y la compañía, entre aquellos y los directivos, entre los acreedores y la sociedad, entre la sociedad y los proveedores, etc.

Una segunda dirección, es la denominada Teoría de la agencia. Según esta, los directivos (o management) tienen que supervisar el proceso de negociación voluntaria y los acuerdos entre los distintos actores que participan en las actividades de la sociedad. Estos directivos, son los agentes de los accionistas. El Consejo, contrata a la dirección de la compañía, para que gestione esta en beneficio de los accionistas, ya que estos no tienen ni el tiempo ni los conocimientos necesarios. Los accionistas, al tener que controlar la gestión de los directores (para evitar que estos actúen en beneficio propio, o de forma no diligente), incurren en los denominados costos de agencia. En la reducción de estos costos, es en lo que pone su énfasis esta teoría.

Una tercera dirección, dentro de la escuela del análisis económico del derecho, es la denominada "Transactions Cost Theory», cuyas raíces se hunden en la obra de Ronald Coase ${ }^{17}$ en los años 30. Este profesor defendía que las sociedades existían para reducir los costos de transacción que se dan en cualquier mercado. Agrupando estos costos, entorno a las sociedades, siempre serían más reducidos que en los que incurren los individuos actuando en el mercado de forma aislada. Así

16 Ver en p. 14 de este trabajo, quiénes son considerados como stakeholders. 1937.

17 Coase, R., The nature of the firm. Chicago. Ed: The University of Chicago Press. 
pues, el derecho de sociedades tendrá como objetivo la organización de la compañía y sus relaciones exteriores, al objeto de reducir los costos de transacción en los que se incurre en el mercado. Esta teoría fue desarrollada por Oliver Williamson ${ }^{18}$.

Y finalmente, debemos mencionar la obra de Oliver Hart ${ }^{19}$, en la que conceptualiza a la sociedad como un conjunto de derechos de propiedad. Según la misma, el derecho de propiedad es el concepto fundamental que es capaz de explicar la complejidad de la sociedad. La sociedad es definida como un conjunto de Derechos, que pertenecen a la sociedad. En este contexto, el derecho de propiedad, es visto como el derecho a ejercer los «derechos residuales de control» ${ }^{20}$.

Podemos finalizar diciendo que muchos, aunque no todos, de los autores que defienden el análisis económico del derecho, propugnan la maximización del valor de la sociedad, en beneficio de los inversores (o accionistas) como el principal fin de la sociedad ${ }^{21}$. Por lo tanto, y en conjunto, son unos fervientes defensores de la Shareholder Primacy.

Por el contrario frente a estas posiciones también denominadas nominalistas o agregadas (ya que, recordamos, según ellas las sociedades son meras ficciones y suma de los contratos, o de los derechos de propiedad de todos los participes en la sociedad), la doctrina anglosajona ha alumbrado diferentes teorías que tienen su origen en la conceptualización de la sociedad como una entidad con personalidad distinta a la de sus socios. Estas son las denominadas «Real Entity Theories». Estas teorías han tenido un mayor desarrollo en la Europa continental que en el mundo anglosajón. Entre ellas podemos incluir el modelo del «contrato social» y la denominada teoría "orgánica».

Dentro de este grupo podemos incluir a las denominadas «Communitarian» o "Progressive theories» (que aquí y por comodidad denominaremos sin más Comunitarias), que tiene muchas semejanzas con la stakeholdes theory que luego veremos con mayor detalle. Esta corriente doctrinal, defiende que las grandes compañías cotizadas, son instituciones públicas, y no privadas. Entiende la sociedad como una comunidad interdependiente, de confianza mutua y beneficio recí-

18 Wiliamson, O., «The Vertical Integration of market production:Market Failure Considerations», en American Economic Review, vol. 61 de 1971.

19 Grossman, S. and Hart, O., «The Cost and Benefits of Ownership: A Theory of Vertical and Lateral Integration», en Journal of Political Economy, vol. 94 de 1986.

20 Armour, J. y Whincop, M., "The property foundations of Corporate Law», en Oxford Journal of legal Society, vol. 27 de 2007, p. 429.

21 Ver, por todos, Black, B. y Kraackman, R., «A self-enforcing Model of Corporate Law», en Harvard Law Review, vol. 109 de 1996. 
proco. La mayoría de estos autores son «anti-contractualistas» en su visión de la compañía. Más que por estar preocupados por la reducción de los costos de transacción, lo que les interesa son los efectos sociales de la actividad de la sociedad. Rechazan la idea de que las distintas partes o sujetos que contratan con la sociedad, tengan la posibilidad de defender sus intereses en igualdad de condiciones para con la sociedad, y por lo tanto exigen normas imperativas, y una mayor regulación para otorgar adecuada protección a los más débiles. ${ }^{22}$

Los Comunitaristas han criticado duramente a la escuela del análisis económico del derecho, por estar demasiado centrada en el interés del individuo y por extensión, también la obsesión por el beneficio de la Shareholder Primacy Theory. Lo cierto es que los primeros dan más importancia a los valores sociales y políticos, a la dignidad humana y a al bien común ${ }^{23}$, así como a los valores y metas de la sociedad en la que viven, por lo que los vínculos culturales de las personas con su entorno deberán ser siempre respetados.

Pero dicho esto, el modelo "Comunitarista» difiere del Stakeholder model, en que los defensores de este último, tal y como veremos, hacen hincapié en la «eficiencia» de las relaciones jurídicas y económicas y en dar gran importancia al papel que los directivos han de jugar en la gestión de la sociedad. El management tiende a distraerse o buscar sus propios intereses, por lo que es necesario idear mecanismos de control de estos. Por el contrario los primeros creen en el sentido de justicia y profesionalidad de los directivos, confiando ciegamente en su honradez y, por tanto, no dando ninguna importancia a las formulas de fiscalización.

Además y como variables de los anteriores señalar la «Team Production Theory», desarrollada por Blair y Stout ${ }^{24}$, y el argumento de Elhauge ${ }^{25}$ según el cual los managers deben de tener la capacidad de sacrificar beneficios en interés de la sociedad. Según la primera, la so-

22 Millon, D., «New Directions in Corporate Law: Communitarians, Contractarians and Crisis in Corporate Law», En Washigton and Lee Law Review, vol. 50 de 1993, pp. 1373 y ss.

${ }^{23}$ Con lo que enganchan con la doctrina social de la Iglesia Católica, una vez algunos de estos autores se han desprendido de ciertos conceptos pseudo-marxistas, felizmente superados.

24 Blair, M. y Stout, L., «A Tean Production Theory of Corporate Law», en Virginia Law Review, vol. 85 de 1999.

25 Elhauge, E., "Sacrifiing Corporate Profits in the Public Interest», en New York University Law Review, vol. 80 de 2005, p. 733; Lee, I.B., «Efficiency and Ethics in the debate about Shareholder Primacy», en Delaware Journal of Corporate Law, vol. 31 de 2006. p. 533. 
ciedad es un conjunto de equipos al que todos los steakholders contribuyen, y en la que el órgano de administración, integrado por consejeros independientes, ha de dirigir e individualizar cual de los distintos equipos de stakeholders debe, en cada momento realizar un mayor esfuerzo. En correlación con el mismo se determina a cual o cuales de ellos asignar —en proporción al trabajo realizado- los beneficios obtenidos.

Aunque Blair, Stout y Elhauge, están ideológicamente lejos de las posiciones «Comunitaristas» a la hora de criticar la Shareholder Primacy, su contribución es interesante, precisamente por realizar su crítica desde posiciones que defienden —al igual que la Escuela de Chicago- posiciones de eficacia económica. «Hablan» el mismo lenguaje que los defensores de la SP. Consecuentemente, sus criticas han sido objeto de un respetuoso análisis por parte de los defensores de aqueIla. Si bien su apuesta por el criterio normativo de la eficacia les lleva a adoptar una empobrecida posición ética.

Dicho todo esto, y citando al profesor australiano Stephen Bottomley «I have noted the breadth and diversity of the corporate world and I have commented on the pitfalls of attempting to devise a grand theory for all corporations in all contexts» 26 .

Seguidamente, vamos a entrar en el análisis de las dos teorías que, en la práctica, son adoptadas por los ordenamientos jurídicos de los países más desarrollados del planeta. En su exposición utilizaremos el guión seguido, e estos efectos por Andrew Keay en el capítulo 2 de su libro «The Enlightened Shareholder Value Principle and Corporate Governance» ${ }^{27}$.

\section{The shareholders value o Shareholder primacy theory}

El término Shareholder Value fue utilizado por primera vez por consultores Norte Americanos en 1980. Durante los últimos 30 años ha sido la teoría que, aún con detractores, más influencia ha tenido en la doctrina societaria anglosajona (no sólo Norteamericana, Británica y Canadiense, sino que también la Australiana — cada vez más influyente - y la Neo Zelandesa). Esta teoría, postula que la gestión que de la sociedad realizan sus administradores, esta definida y limitada por

26 Bottomley, S., The Constitutional Corporation. Ed: Ashgate Publishing Limited. Burlington Vermont, USA. 2008. p. 17.

27 Keay, A., The Enlightened Shareholder Value Principle and Corporate Governance. Ed: Routledge, New York. 2013. pp. 14 y ss. 
la obligación que estos tienen para con los accionistas de la sociedad. Cualquier otra responsabilidad es secundaria. En esta teoría, los intereses de los stakeholders distintos de los accionistas, son relevantes, en la medida en la que sirven para obtener el objetivo de maximizar el valor de la acción, y por lo tanto la riqueza de los accionistas.

El pistoletazo de salida, al arrollador éxito de esta teoría, lo sitúa la doctrina en la publicación, por parte de Milton Friedman, en un número del New York Times Sunday Magazine de 1970, de un artículo en el que el Premio Nobel aseguraba que como los accionistas son los «propietarios de la sociedad» 28 , la obligación de la dirección de la empresa tienen que ser incrementar sus ganancias. Esta premisa, que fue aclamada con inusitada vehemencia, fue reforzada por la publicación del quizás todavía más influyente paper de M. Jensen y W. Meckling titulado "Theory of the firm: Managerial behaviour, Agency Costs and Ownership Structure ${ }^{29}$ » de octubre de 1976. Este posicionamiento a favor del incremento del valor del accionista como fin u objetivo de la sociedad, y por lo tanto, límite y frontera con respecto a las facultades de gestión de los directivos y administradores; ha sido uno de los pilares esenciales de la denominada teoría del análisis económico del derecho. Teoría que, de forma un tanto pretenciosa, ha sido definida como "the most successful intelectual movement in the law in the last thirty years ${ }^{30} \gg$.

El hecho es que para el final del siglo xx, la mayoría de la doctrina, reguladores y líderes empresariales, aceptaban sin cuestionárselo, que el incremento del valor para el accionista, era el único objetivo del órgano de administración de las sociedades ${ }^{31}$. El momento álgido de esta doctrina fue la publicación en el año 2001, en el Georgetown Law Journal del ensayo titulado «The end of History for Corporate Law» de los profesores Kraakman y Hansmann ${ }^{32}$ quienes afirman que

....academic, business, and governmental elites that ultimate control over the corporation should rest with the shareholders class; the

${ }^{28}$ Ver en http://www.colorado.edu/studentgroups/libertarians/issues/friedman-socresp-business.html. Texto completo del artículo publicado el 13 de septiembre de 1970.

29 Jensen, M. y Meckling, W., "Theory of the firm: Managerial behavior, Agency Costs and Ownership Structure», en Journal of Financial Economics, vol. 3, N4. October, 1976, p. 305.

30 Teles, S., The rise of the conservative legal movement: The battle for control of the law. Princetown University Press. Princetown. 2008, p. 216.

31 Stout, L., The Shareholder Value Myt Ed:Berrett-Koehler Publishers Inc. San Francisco. 2012, p. 21.

32 Kraakman, R. y Hansmann, H., The end of History of..., op. cit., pp. 2 y 3. 
managers of the corporation should be charged with the obligation to manage the corporation in the interest of its shareholders; other corporate constituencies, such as creditors, employees, suppliers and customers, should have their interest protected by contractual and regulatory means rather than through participation in corporate governance; .... and the market value of the publicly traded corporation's shares is the principal measure of the shareholders' interest.

para continuar con «The triumph of the shareholders oriented model of the corporation is now assured». La SEC Norteamericana, durante los últimos casi 30 años, no ha hecho más que adoptar medidas encaminadas a ensalzar esta teoría, así como la participación de los accionistas en el Gobierno Corporativo de las sociedades. Como paradigma de esta legislación, esta la SOX ${ }^{33}$.

La razón aducida, para defender antes que nada los intereses de los accionistas, tiene sus raíces en conceptos económicos, legales y filosóficos creados - o en algunos casos adoptados- por la escuela del análisis económico del derecho. Según los defensores de la Shareholder Primacy, los accionistas son los acreedores residuales de la compañía 34 , es decir, los accionistas se beneficiaran los que más (y en relación con otros steakholders como los acreedores, los trabajadores, proveedores, clientes y comunidad) si la compañía gana dinero; pero, sin embargo perderán todo su capital si a la sociedad le van mal dadas. Es decir, en caso de liquidación de la sociedad, son los últimos a la hora de poder resarcirse de las pérdidas con el patrimonio social que, en su caso, resulte de aquella. Por lo tanto, son los más interesados en los resultados de la compañía, teniendo un especial interés en cada decisión que tome la sociedad 35 .

Esta teoría, tiene una serie de ventajas importantes, en relación con la Stakeholder Theory. Es, en primer lugar y sobre todo, una teoría clara. Es decir, es posible el evaluar si los directivos están o no, maximalizando el valor de los accionistas

A diferencia de lo que defendía la teoría de la agencia antes expuesta, la dirección de la empresa, ha de ser responsable ante la propia sociedad, no ante los accionistas; es decir al management le contrata

33 Sarbanes Oxley Act. Ver en http.//www.sec.gov/abaut/laws/soa2001.pdf. Aprobada el 30 de julio de 2002.

34 Residual claimants, que a los efectos que aquí nos ocupan, traducimos como «acreedores residuales».

35 Macey, J., «Fiduciary duties as Residual Claims: Obligations to Nonshareholder Constituencies from a theory from the firm Perspective», en Cornell Law Review, vol. 84 de 1999. Keay, A., «The Enligted Shareholder...», op. cit., 9. 18. 
la sociedad. El argumento de la eficacia nos dice, que como los directivos solo tienen que concentrarse en el interés de un grupo, esto les permite trabajar más eficientemente.; pero la realidad nos muestra que realmente no es tán eficiente ya que la retención de beneficios desmesurados para los accionistas, en muchas ocasiones puede ocasionar daños colaterales a terceras partes como son los trabajadores, o a la comunidad en la que la sociedad radica.

Otro argumento es la certeza. Se dice que es una teoría más pragmática, en el sentido de que suministra un criterio claro para determinar si se alcanza el éxito en la gestión del negocio, así como una guía clara para el management para saber cuál es la dirección que hay que tomar para alcanzar ese éxito. Pero contra este argumento de gran peso esta el de la indeterminación del tiempo en el que deberá de alcanzarse el éxito. No es lo mismo el corto, que el largo plazo ${ }^{36}$. En relación con esto Cuando la dirección adopte una decisión, ¿en qué accionistas tendrá que pensar, los actuales, o los que lo sean en un futuro? ${ }^{37}$. Es muy posible, además, que no todos los accionistas tengan los mismos intereses económicos, con lo que será difícil el adoptar medidas en el interés de todos ellos.

Los defensores del Shareholder Primacy Model hacen especial hincapié, en el argumento de que este modelo, es también bueno para la sociedad en general ya que incrementa el bienestar en términos generales. Como dice Andrew Keay ${ }^{38}$, la idea es que el sacrificio del resto de stakeholders en este paradigma pro-accionista, será compensado con un incremento de la riqueza de los accionistas que, al final redundará en toda la sociedad ${ }^{39}$. No obstante este argumento ha sido muy criticado, por entender un sector importante de la doctrina que el bienestar de la sociedad en su conjunto, no se incrementa cuando el foco de la actividad esta puesto en las ganancias a corto plazo ${ }^{40}$. Además, y tal y como también esta argumentado por Kent Greenfield ${ }^{41}$ sin un me-

${ }^{36} \mathrm{Hu}, \mathrm{H}$., «Risk, Time and Fiduciary Principles in Corporate Investment», en University of California at Los Ángeles Law Review. vol. 38. 1.990.

37 Keay, A., "Shareholder Primacy in Corporate Law: Can it Survive?», en European Company and Financial Law Review, vol. 7, 2010, p. 369.

38 Keay, A., "The enlightened Shareholder Value...», op. cit., p. 29.

39 Lee, I., "Efficiency and Ethics in the Debate About Shareholder Primacy», en Delaware Journal of Corporate Law, vol. 31 de 2006, p. 533.

40 Loderer, J. et al., "Shareholder Value: Principles, Declarations and Actions». April 22, 2009. European Corporate Institute Working Paper No 95/2006. Ver en http:// papers.ssrn.com/sol3/papers.cfm?abstract_id=690044

41 Greenfield, K., "Saving the world with Corporate Law», en Emory Law Journal, vol. 57 (2008), p. 947 
canismo que obligue a los accionistas a compartir sus ganancias con otros stakeholders, es seguro que estos últimos no recibirán nada. O muy poco.

Un último argumento utilizado por los defensores de esta teoría y que enlaza con la idea de que los accionistas tienen una posición débil que debe ser mimada por los directores y el consejo, es que es imposible el recoger en un contrato todas las posibles situaciones a las que los directores de la sociedad, tendrán que enfrentarse, así que, esta teoría servirá para subsanar esas posibles fallas contractuales, en el sentido de que la dirección o management de la compañía siempre deberá quedar obligada con los accionistas.

Vamos a realizar un rápido repaso a las críticas realizadas. La primera es que existe la percepción extendida de que esta teoría exige al management de la compañía que gestione la misma, centrados en el corto plazo ${ }^{42}$. Esto obviamente daña el desarrollo de la compañía y sacrifica el valor de la misma a largo plazo.

Tiene además un acercamiento a la realidad estrecho, ya que dada la complejidad de la actual sociedad, no es posible el que los directores se centren en un único objetivo, además, continúan los críticos, esta teoría reduce todo a un tema de beneficios ${ }^{43}$.

Además el énfasis en el interés de los accionistas, no nace de ninguna razón ética o moral, si no solamente de la necesidad de ser eficiente. No hay ninguna consideración a valores como la justicia, equidad, o igualdad. Por lo tanto muchos estudiosos ven esta teoría como desafecta a la dimensión humana que es fundamental en todas las facetas de la vida, incluidos los negocios.

\section{The stakeholder theory}

El padre de la Stakeholder Theory moderna es R. Edward Freeman, quién publico sus ideas al respecto, en su influyente libro "Strategic Management: a Stakeholder Approach ${ }^{44}$. Esta teoría, aunque de forma parcial, sirve como guía para la actuación de la dirección y el ór-

42 Millon, D., «Why is Corporate Management obsessed With Quarterly Earnings and What Should be Done about it?», en George Washigton Law Review, vol. 70 de 2002, p. 890.

43 Wood, D., «Whom should Business serve?», en Australian Journal of Corporate Law, vol. 14, 2002, p. 1.

44 Freeman Edward, Strategic Management: a Stakeholder Approach. Ed: pitman/ Ballinger. Boston. 1984. 
gano de administración de la sociedad en varios países, entra los que vamos a destacar por su importancia Japón y Alemania.

Ahora bien, antes de continuar tenemos que dar un concepto del término «stakeholder» (o «interesado» ${ }^{45}$, como de forma poco feliz ha sido incorporado a nuestro idioma). Es un vocablo vago y confuso, que al no haber sido objeto de regulación legal en ningún país (solamente ha sido incorporado a textos sin fuerza legal, o soft law, como es el caso de las Códigos de Gobierno Corporativo de Sociedades Cotizadas) ha quedado al arbitrio de las necesidades doctrinales. Señalar de forma muy breve que Phillips ${ }^{46}$, realizó, sobre la base de los trabajos de Hart y Rawls, una aproximación al termino, haciendo una división entre un concepto «amplio» o «derivativo» y otro «estrecho» o «normativo» de stakeholder. El primero, tiene su base en la definición que realiza el propio Edward Freeman, según la cual serán stakeholders «those who can affect or are affected by the achievement of the firm's objectives». Es una definición realmente amplia en la que, según algunos estudios, se pueden catalogar hasta 100 grupos y subgrupos distintos ${ }^{47}$. Por el contrario, la concepción «estrecha» concluye que solamente aquellos grupos, frente a los que es debida una obligación moral, serán stakeholders. Con respecto a estos, sí que existe un consenso muy amplio de que los diferentes grupos que integran este concepto, son los siguientes: Accionistas, trabajadores, proveedores, clientes, y la comunidad en la que la sociedad radica.

Volviendo al fondo de la cuestión, señalar que los dos fundamentos sobre los que descansa esta teoría, son los siguientes: Primero: además de los accionistas, hay otros interesados que contribuyen al éxito de la compañía. Segundo, existen diversos grupos de stakeholders, además de los accionistas, que se ven afectados por las decisiones que toma la compañía. En efecto, otros stakeholders, distintos de los accionistas, también invierten en la sociedad (los trabajadores su trabajo, los acreedores su dinero con riesgo, los proveedores tienen un derecho de propiedad sobre lo que proveen a la compañía, hasta que esta se lo paga, ${ }^{48}$ etc.), y si no se les tiene en cuenta, acabaran por abandonar la sociedad e irse a otra en la que se les reconozcan sus méritos.

45 En este trabajo, utilizaremos de forma indiferente los términos stakeholder e interesados.

46 Phillips, R., "Stakeholder Legitimacy», en Business Ethics Quarterly, vol 13 de 2003, pp. 25 a 41.

47 Fassim, Y., "The Stakeholder Model Refined», en Journal of Business Ethics, vol. 84 de 2009, p. 113.

48 Freeman, R.E. y Phillips, R., "Stakeholder Theory: A Libertarian Defense», en Business Ethics Quarterly, vol. 12 de 2002, p. 331. 
Andrew Keay, pone de nuevo el dedo en la llaga al afirmar que "Stakeholder approach in general terms is premised on the notion that inclusión from a social, economic and political perspective is valuable; and the theory focuses on fostering the full potential of all contributors» ${ }^{49} \mathrm{El}$ ideal del "Stakeholderismo» es que todos los interesados trabajen juntos para conseguir un fin común, que no es otro que obtener beneficios para todos. Otro de los padres de la StekeholderTtheory, Clarkson, aseguraba que «The economic and social purpose of the Corporation is to create and distribute wealth and value to all its primary stakeholders groups, without favoring one group at the expense of others» ${ }^{50}$ A diferencia de la Shareholder Primacy, ningún grupo tiene prioridad sobre otro ${ }^{51}$.

Un elemento fundamental de la teoría, es que las sociedades tienen que estar gestionadas, en beneficio de y ser responsables ante todos los «interesados». Trata de aportar un mecanismo, a través del cual los intereses de todos los stakeholders puedan ser coordinados. Producto de esta coordinación y de la justicia distributiva, es la legitimación de los stakeholders a tener una participación en los beneficios sociales.

A diferencia de lo defendido por la SP (que se centra en la eficiencia), la STKT abraza otro tipo de valores (aunque sin rechazar la eficacia), como son la justicia, la confianza y la cooperación. Trata de combinar aspectos económicos y éticos, y al hacerlo "domestica el aspecto más duro del capitalismo» ${ }^{52}$. Por todo ello, son muchos los tratadistas que incluso abogan por dar entrada a los stakeholders en los procesos de formación de la voluntad de la sociedad ${ }^{53}$.

49 Keay, A., The Corporate Objetive. Ed: Edward Elgar Publishing Limited. Chentelham. U.K. 2011, p. 94.

50 Clarkson, M.: «A Stakeholder framework for Analizing and Evaluating Corporate Social Performance», en Academy Management Review, vol. 20 de 1995, p. 92.

51 Omran, M.; Atrill, P. y Preston, L., "Shareholders versus Stakeholders: corporate mision statements and investors Returns», en Business Ethics: a European Review, vol. 11 de 2002, p. 318.

52 Plender, J., A Stake in the Future: The Stakeholder Solution. Ed: Nicolas Bradley Publishing. London. 1997, en Keay, A., «The Corporate ...», op. cit., p. 71.

53 Greenfield, K., The failure of Corporate Law. Ed: The University of Chicago Press. Chicago. 2006, pp. 181 y 182. Asimismo, ver Roth, M., «Employee participation, Corporate Governance and the firm: A Trasatlantic View Focused on Occupational Pensions and Co-determination», en European Business Organization Law Review, vol. 11 de 2010, p. 11; en el que se realiza una nueva aproximación a la posible participación de los empleados en el Consejo de Administración. En este caso el autor lo que plantea es que los trabajadores accedan como representantes de los fondos de pensiones que toman participaciones en sociedades cotizadas. 


\section{Criticas}

Son muchas las críticas recibidas por esta teoría. Una de ellas afirma carece de base legal, por lo que su implementación deviene imposible. Es una teoría, prosiguen sus críticos, cuyos fundamentos más importantes son morales. Es decir, esta construida sobre la base del deber deontológico de tratar a todas las personas por igual y sobre la visión neokantiana del respeto a los demás (de ser todos iguales); lo cual nos lleva a ver a las personas no como medios para alcanzar un fin, sino como fines en sí mismos. ${ }^{54}$ Frente a esta posición ética, la ácida crítica del sector más radical de la escuela del análisis económico del derecho, la ha tildado de "naive, superficial and unrealistic» ${ }^{55}$ incluso se ha dicho que no tiene ni el status de teoría, que simplemente es una línea de investigación ${ }^{56}$.

Al carecer de fundamentos legales a la hora de justificarla, hace que los directores o management de las sociedades no encuentren argumentos para preferir la Stakeholder Theory a cualquier otra teoría o doctrina que trate de dar cobertura al aspecto moral de cuál ha de ser el fin de la sociedad.

Se dice además que es una construcción que no es clara. En efecto, el aspecto más complicado de esta teoría, es la obligación que tienen los administradores de sopesar, o equilibrar, los intereses contrapuestos que existen entre los diversos stakeholders. Aunque todos los grupos de interesados deben de ser tratados por igual, no todas sus demandas y necesidades son semejantes, o tienen la misma importancia en una situación determinada. De hecho y, al igual que comentábamos cuando realizábamos la crítica a la Shareholder Primacy, aquí también pueden existir divergencias de intereses, no sólo entre los distintos grupos de stakeholders, si no también dentro de cada grupo (así acreedores a corto o largo plazo, o con distinta clase de garantías). La dificultad final es el determinar las bases del equilibrio. El problema es que no existe una guía o criterio para asignar un peso relativo en la sociedad a cada grupo. La consecuencia de esta falta de claridad

54 Gibson, K., "The moral basis of Stokeholder Theory», en Journal of Business Ethics, vol. 26 de 2000, p. 245. Ver, también, Fisch, J., "Measuring Efficiency in Corporate Law: The Rule of Shareholder Primacy», december 2005, Fordham Law Legal Studies, Working Paper n. ${ }^{\circ} 105$, p. 29, en http://ssrn.com/abstract=878391. Última entrada, 15 de junio de 2012.

55 Stoney, C. y Winstanley, D., «Stakeholder Confusion or Utopia? Mappinig the Conceptual Terrain», en Journal of Management Studies, vol. 38 de 2001, p. 600.

56 Learmount, S., «Theorizing Corporate Governance: New Organizational Alternatives», en Journal of Interdisciplinary Economics, vol. 14 de 2003. 
puede afectar a la dirección de la sociedad en dos sentidos distintos. Uno sería la dirección estratégica clara para el management al tener que perseguir objetivos muy diferentes; y el segundo sería el que amparándose en sus obligaciones ante los distintos grupos de interesados, la dirección se volviese «incontrolable» ya que cualquier acción u omisión que vulnerara los deberes de diligencia y lealtad, sería siempre más fácilmente eludible.

En efecto, a diferencia de la Shareholder Primacy ( en la que los accionistas si que pueden ejercitar la acción social de responsabilidad, para exigir a los administradores que actúen en beneficio de la sociedad, o lo que es lo mismo y según interpretación totalmente extendida - en beneficio de los accionistas-), en la STKT, excepto los accionistas, ningún otro grupo está facultado para el ejercicio de acción alguna en defensa de sus intereses. Es decir, no pueden solicitar de los administradores la toma de decisiones que les beneficien como grupo (y junto a los otros grupos).

\section{Estado práctico de la cuestión en EE.UU. y en el Reino Unido}

Comentadas someramente las dos principales teorías, vamos a realizar una breve exposición de cual es el estado de la cuestión en la práctica, tanto en EE.UU. como en el Reino Unido. Comenzando por los americanos, señalamos, que han sido vistos siempre como el bastión del Shareholder Value o Primacy; aunque, tal y como veremos se han producido una serie de acontecimientos, que, de forma tímida, nos permiten atisbar una ligera inclinación hacia la teoría del «stakelholderismo». Efectivamente, durante los 30 últimos años, se ha producido, la aprobación, por 40 Estados Americanos, de lo que se ha dado en denominar como "Constituency Statutes», "Stakeholder Statutes», o «Non-shareholder Statutes». Es decir, son modelos de estatutos, para sociedades, aprobados por los Parlamentos de los Estados Federados, en los que tal y como veremos, se permite que la dirección y el Consejo de Administración de la Sociedad, a la hora de tomar sus decisiones, tenga en cuenta el interés, no sólo de los accionistas, si no también el de otros stakeholders. Avanzamos desde ahora, que, en su mayoría, simplemente "permiten», no «obligan» a nada.

Para el profesor de UCLA, S. Bainbridge, la aprobación de estos estatutos ha sido "The most significant change in United States Corporate Law since the New Deal scurities laws, or even the enabling codes of the last century (Diecinueve), and they were potentialy 
revolutionary» ${ }^{57}$ Ya veremos como, desgraciadamente, ha quedado, por ahora, en una mera modificación formal de escasa - por no decir nula- transcendencia práctica.

El primero de estos estatutos fue aprobado en 1983 por el Estado de Pennsylvania, y tiene su base intelectual en la disputa que enfrento, en los años 30 a los profesores Berle y Dodd58, relativa a con respecto a quienes estaban obligados los directores de las compañías a la hora de tomar sus decisiones. Todos estos estatutos, tienen en común que permiten al Consejo de administración de las sociedades cotizadas, el considerar, un grupo de interesados más amplio (que solamente el de los accionistas), cuando tomen decisiones en beneficio de la sociedad, o más precisamente, tomar decisiones que afecten a la marcha de los negocios sociales ${ }^{59}$. Estos estatutos, requieren ${ }^{60}$, o permiten ${ }^{61}$ a los directores y al Consejo tomar en consideración los intereses de varios grupos de stakeholders. Entre los grupos más citados están (además de los accionistas) los empleados, los proveedores, clientes, acreedores y las comunidades donde están situadas las sociedades. Como vemos, coinciden por los grupos generalmente aceptados por la doctrina antes mencionada (ver Supra). Y, asimismo, mientras algunos Estados (Idaho, Nuevo México, Mississippi, Ohio, y Wyoming), exigen expresamente tener en cuenta los intereses de los accionistas junto a los de los stakeholders, en otros, como Indiana y Pennsylvania, prohíben el beneficiar a un grupo concreto de stakeholders. Arizona e Idaho, van más allá, y exigen a los directores, tener en cuenta, el largo plazo de la sociedad.

No obstante, tal y como antes hemos avanzado, la realidad es bastante distinta. Para un sector de la doctrina ${ }^{62}$ estos estatutos «By at-

57 Bainbridge, S., «Interpreting Nonshareholders Constituency Statutes», en Pepperdine Law Review, vol. 19 de 1992, p. 971.

58 Dodd, E.M., "For Whom are Corporate Managers Trustees?», en Harvard Law Review», vol. 45 de 1932, p. 1.145. También, y a este respecto, ver Bratton, W.W. y Watcher, M.L., "Adolf Berle and the Modern Corporation», en The Journal of Corporate Law. vol. 34 de 2008, p. 99.

59 Macey, J., «Fiduciary Duties as Residual Claims: Obligations to nonshareholders Constituencies From a Theory of the Firm Perspective», en Cornell Law review, vol. 84 de 1999, p. 1.266.

60 Como los de CONNECTICUT: CONN. GEN. STAT. S.33-313 (2003); ARIZONA: ARIZ. REV. STAT. S.10-1202 (2002); IDAHO CODE s. 30-1602 (2002); en Keay, A., "The Enlightened Shareholder Value...», op. cit., p. 188.

61 INDIANA, IND. CODE, s. 23-1-35-1(d); OHIO REV. CODE. ANN, s. 1701.59 (E) (Supp. 1989), en Keay, A., "The Enlightened Shareholder Value...», op. cit., p. 188.

62 Adams, E. y Matheson, J., "A Statutary Model for Corporate Constituency Concerns», en Emory Law Journal, vol. 49 de 2000. Ver, también, Leung, W., "The Indecuancy of Shareholder Primacy: A Proposed Corporate Regime That Recognizes NonShareholder Interest», en Columbia Journal of Law and Social problems, vol. 30 de 1997. 
tempting to reach too many varying interest, constituency statutes fall to probide a benchmark for shareholders and stakeholders to hold directors accountable of their decissions». A esto hay que añadir el hecho de que los Juzgados no han sabido cómo aplicar estos estatutos, con independencia, o superando la omnipresente Shareholder Primacy. ${ }^{63} \mathrm{El}$ hecho cierto es que estos estatutos, ni en el campo de la práctica legal, ni en los tribunales ${ }^{64}$ han tenido los resultados esperados. Son, efectivamente, casi inexistentes los procedimientos judiciales en los que se ha demandado a los administradores por no haber tenido presentes los intereses de los stakeholders. Hay registrados solamente tres casos, en los cuales, además, los jueces no han seguido una actuación uniforme ${ }^{65}$. Podemos afirmar, por lo tanto, que estos "Constituency Statutes» no han tenido un impacto directo, en la práctica societaria Norte Americana. Quizás ante la desilusión creada, algunos autores, con más voluntarismo que pragmatismo afirman que estos estatutos, al menos, reflejan un profundo reconocimiento, desde el punto de vista ideológico y moral, de la necesidad de valorar los intereses de los stakeholders en la toma de decisiones por parte de la dirección de la empresa.

En el Reino Unido, la aprobación de los Constituencies Statutes, que acabamos de comentar, tuvo su reflejo en el denominado principio del Enlightened Shareholder Value (ESV). En efecto, 1998 se creo en este país, el denominado Company Law Review Steering Group (CLRSG), con el objetivo de reformar el Derecho de Sociedades Británico. En síntesis ${ }^{66}$, y tras varios trabajos y publicaciones, el mencionado grupo propuso que, en la nueva Ley de Sociedades, el beneficio de los accionistas fuera el objetivo final de la compañía, pero eso sí, atemperado por el ESV. Según el CLRSG, este principio debe informar la actuación del Consejo y dirección de la compañía, en el sentido de gestionarla en el beneficio colectivo de todos los accionistas, pero, teniendo en cuenta intereses de otros grupos de stakeholders. Finalmente todo el trabajo realizado por el grupo ha tenido su colofón en la nueva sección 172 de la Companies Act Britanica de 2006, la cuál dispone que:

63 Bisconti, A., «The double Bottom Line: Can Constituency Statutes Protect Socially responsables Corporations Stuck in Revlon Land?», en Loyola Los Ángeles Law review, vol. 42, de 2009, p. 765.

64 Oswald, L., «Shareholders v Stakeholders: Evaluating Constituency Statutes under the Takings Clause», en Journal of Corporation Law, vol. 23 de 1997, p. 1.

65 Ver en Keay, A., «THe Enlghtened Shareholder Value...», op. cit., p. 196.

66 Para más información, y tener acceso a los trabajos publicados por este grupo, además de los debates parlamentarios, ver: http://www.legislation.gov.uk/ ukpga/2006/46/contents. Última entrada, 20 de enero de 2013. 
A director of a company must act in a way that he considers, in good faith, would be most likely to promote de success of the company for the benefit of his members as a whole, and in doing so have regard (amongst other matters) to:

(a) The likely consequences of any decision in the long term.

(b) The interest of the company's employees.

(c) The need to foster the company's business relationships with suppliers, customers and others.

(d) The impact of the company's operations on the community and the environment.

(e) The desirability of the company maintaining a reputation for high standards of business conduct, and

(f) The need to act fairly between the members of the company.

\section{Breve análisis comparado de la situación en los códigos de gobierno corporativo}

En este apartado, vamos a realizar un rápido repaso por los códigos de buen gobierno de un conjunto de países. Nos centraremos en las referencias que en los mismos, se realizan a cual ha de ser el fin de la sociedad, o dicho de otro modo, cual es el objetivo que debe perseguir el Consejo de Administración y el management de la compañía en sus labores de dirección y gestión de la empresa. Los países elegidos, lo han sido siguiendo el criterio de tratar de dar una visión global del actual estado de la cuestión, y combinando por lo tanto economías desarroIladas, con las de países emergentes. En Alemania, en el apartado 4.1.1 del Código de Gobierno Corporativo de 15 de mayo de 2012, se dice que el Consejo de Administración deberá gestionar la sociedad, «en interés de la sociedad, y por lo tanto, tomando en consideración el interés de los accionistas, de los empleados, y de otros stakeholders, con el objetivo de la creación de valor de forma sostenible ${ }^{67}$ ». En este código, efectivamente, encontramos en plano de igualdad los intereses de todos los stakeholders. Podemos afirmar, sin ningún género de dudas, que este código está claramente influenciado por la Stakeholder Theory. En Francia68 en sus «Recomendaciones de Gobierno Corporativo» de marzo de 2011, se dice que el Consejo actuará en el interés de

67 Ver en http://www.ecgi.org/codes/documents/cg_code_germany_15may2012_ en.pdf. Última entrada, 15 de enero de 2013.

68 Ver en http://www.ecgi.org/codes/documents/cg_recommendations_afg_2011_ en.pdf. Última entrada, 15 de enero de 2013. 
los accionistas, aunque deberá prestar «atención» a las cuestiones sociales y medio ambientales. Nos encontramos con un claro exponente de la Shareholder Primacy. Australia ${ }^{69}$ en sus «Corporate Governance Principles and Recommendations» de 3 de junio de 2010, en su principio III además de exigir al Consejo que adopte decisiones de forma ética y responsable, le insta a "considerar» las razonables expectativas de los stakeholders. Tendremos que incluirlo en el grupo de la Shareholder Primacy. En Austria70, el Austrian Code of Corporate Governance, de enero de 2012, en su recomendación decimotercera, exige al Consejo de Administración trabajar «en el interés de los accionistas, de los empleados, y del bien común.» Aunque no se realiza una remisión expresa a los stakeholders, y solo se cita a uno de sus grupos -los empleados - entendemos que los sitúa al mismo nivel que a los accionistas; la incluiremos en el Stakeholder Theory. En la República Popular China $^{71}$ (probablemente porque en las grandes sociedades el Estado sigue siendo el mayor accionista). Realmente, su código (de enero de 2004) es incalificable por la falta absoluta de democracia real y económica en el país. En Canadá72 en su código de enero de 2006, se hace referencia a que el Consejo actuará en beneficio de «la sociedad». Eufemismo, como antes ya hemos dicho, para encubrir el Shareholder Primacy. En Dinamarca ${ }^{73}$ en sus Recomendaciones de Gobierno Corporativo de agosto de 2011 —y aunque socialmente es un país bastante avanzado-, en su recomendación segunda, solamente se exige al Consejo que "tenga una buena relación con los stakeholders» de la sociedad. Claro tanto para la Shareholders Primacy. En Finlandia ${ }^{74}$ según su Código de 15 de junio de 2010, el Consejo sólo está obligado frente a la propia compañía y sus accionistas. En Italia ${ }^{75}$ el «Codice di Autodisciplina» de diciembre de 2011, hace una referencia genérica a actuar en el interés de la propia sociedad. Shareholder Primacy. En Ja-

69 Ver en http://www.ecgi.org/codes/documents/cg_marked_up_amendments_ 30jun2010.pdf última entrada, 15 de enero de 2013.

70 Ver en http://www.ecgi.org/codes/documents/cg_code_austria_jan2012_en.pdf. Última entrada, 15 de enero de 2013.

71 Ver en http://unpan1.un.org/intradoc/groups/public/documents/apcity/unpan 033862.pdf. Última entrada, 15 de enero de 2013.

72 Ver en http://www.ecgi.org/codes/documents/tsx_guide_to_good_disclosure.pdf. Última entrada, 15 de enero 2013.

73 Ver en http://www.ecgi.org/codes/documents/cg_recommendations_denmark_ aug2011_en.pdf. Última entrada, 15 de enero de 2013.

74 Ver en http://www.ecgi.org/codes/documents/finnish_cg_code_2010_en.pdf. Última entrada, 15 de enero de 2013.

75 Ver en http://www.ecgi.org/codes/documents/codice_corpgov_2011_en.pdf. Última entrada, 15 de enero de 2013. 
pón ${ }^{76}$ en sus «Recomendaciones de Gobierno Corporativo para Sociedades Cotizadas» de diciembre de 2009, en su recomendación tercera, después de afirmar que el Consejo trabajará en interés de los accionistas, dice que, no obstante tendrá que tener «buenas relaciones con los stakeholders». Shareholder Primacy. En Noruega77, en el Código de Prácticas de Gobierno Corporativo, de mayo de 2012 (que es de los más avanzados de Europa), se hace expresa mención a la presencia de trabajadores en el Consejo de Administración — siendo un sistema monista- y además se hace un hincapié especial en la Responsabilidad Social Corporativa, por la que el Consejo debe velar. Lo cierto es que no hay ninguna referencia, ni a accionistas ni a stakeholders, en lo referente al tema que nos ocupa. En este caso, no asignaremos el tanto a nadie. Los Principios de Gobierno Corporativo de la OCDE78 de abril de 2004, supusieron un revulsivo, y un modelo de Código que en muchos de sus Principios ha sido copiado hasta la saciedad. En lo que ha nosotros respecta, el Principio IV es rotundo en su título «El papel de los stakeholders en el Gobierno Corporativo» En el mismo se expone. "The corporate governance framework should recognise the rights of stakeholders established by law or through mutual agreements and encourage active co-operation between corporations and stakeholders in creating wealth, jobs, and the sustainability o financially sound enterprises.»

Desgraciadamente, precisamente este Principio, tal y como estamos viendo, casi no ha sido tenido en cuenta por Estado u Organización alguna a la hora de preparar sus Códigos nacionales.

El Código de Gobierno Corporativo de la Comisión Nacional del Mercado de Valores de Portugal79 de enero de 2010, también es una claro ejemplo de orientación shareholder-centric. En efecto, entre sus principios sólo se hace referencia a los accionistas. En Rusia ${ }^{80}$ ocurre exactamente lo mismo. Ni rastro de referencia alguna a los stakeholders. Dos tantos más en el marcador del Shareholder Primacy. En el documento titulado «Regulación del Gobierno Corporativo del Reino de

76 Ver en http://www.ecgi.org/codes/documents/principles_japan_dec2009_en.pdf. Última entrada, 15 de enero de 2013.

77 Ver en http://www.ecgi.org/codes/documents/code_of_practice_norway_ 23oct2012_en.pdf. Última entrada de 2013.

78 Ver en http://www.ecgi.org/codes/documents/principles_en_final.pdf. Última entrada, 15 de enero de 2013.

79 Ver en http://www.ecgi.org/codes/documents/cmvm_cg_recommendations_ 2010_en.pdf. Última entrada, 15 de enero de 2013.

80 Ver en http://www.ecgi.org/codes/documents/final_code_english.pdf. Última entrada, 15 de enero de 2013. 
Arabia Saudí»81, de marzo de 2010, en su artículo 1.a) expresamente se dice que el Consejo velará por que se respeten los derechos de los accionistas y los stakeholders, para continuar con que el Consejo trabajará siempre en el mejor interés de la compañía. Shareholder Primacy. En Singapur ${ }^{82}$ su Código de Gobierno Corporativo de mayo de 2012, en su apartado 1.1.d) nos dice que la labor del Consejo es «identificar los grupos de stakeholders, y ser consciente de que la visión que estos tienen de la compañía, afecta a la reputación de la misma». Claramente Shareholder Primacy. En Sud África el Código King de Gobierno Corporativo para Sud África (también conocido como King III) de septiembre de 2009, determina que el Consejo debe de "considerar los legítimos intereses y expectativas de los stakeholders», e incluso se refiere a un «stakeholder inclusive model», aunque la guía principal, seguirá siendo la de los shareholders. En Suecia ${ }^{83}$ su código de Gobierno de 2010, no hace ninguna mención directa al asunto, remitiéndose a la clausula general de que el Consejo actuará siempre en el mejor interés de la sociedad. En Suiza ${ }^{84}$ en su Código de mejores Prácticas de Gobierno Corporativo de febrero de 2008, se hace una encendida defensa del Sharaholder Value, lo mismo que ocurre en Bélgica ${ }^{85}$ con su Código de 2009, y por supuesto en EE.UU. ${ }^{86}$ en el informe de la N.Y.S.E. sobre Gobierno Corporativo de septiembre de 2010. En el Reino Unido ${ }^{87}$, en el Código de 2012 (y a pesar de lo expuesto en este trabajo sobre el contenido de la s. 172 de la Companies Act de 2006); no se hace mención alguna a los stakeholders. En Holanda88, en su Código de 10 de diciembre de 2008, y en el punto 8 del Preámbulo, se menciona el hecho de que el Consejo «deberá tener en cuenta el interés de los stakeholders». Como vemos una redacción pensada para cumplir el expe-

81 Ver en http://www.ecgi.org/codes/documents/cg_regulations_saudi_arabia_ 16mar2012_en.pdf. Última entrada, 15 de enero de 2013.

82 Ver en http://www.ecgi.org/codes/documents/cg_code_singapore_2may2012_ en.pdf. Última entrada, 15 de enero de 2013.

83 Ver en http://www.ecgi.org/codes/documents/cg_code_sweden_feb2010_en.pdf. Última entrada, 15 de enero de 2013.

84 Ver en http://www.ecgi.org/codes/documents/swiss_code_feb2008_en.pdf. Última entrada, 15 de enero de 2013.

85 Ver en http://www.ecgi.org/codes/code.php?code_id=256. Última entrada, 15 de enero de 2013

86 Ver en http://www.ecgi.org/codes/documents/nyse_cgreport_23sep2010_en.pdf. Última entrada, 15 de enero de 2013.

87 Ver en http://www.ecgi.org/codes/documents/cg_code_uk_sep2012_en.pdf. Última entrada, 15 de enero de 2013.

88 Ver en http://www.ecgi.org/codes/documents/cg_code_netherlands_dec2008_ en.pdf. Última entrada, 15 de enero de 2013. 
diente, pero sin asignar obligaciones concretas. En Méjico ${ }^{89}$, en su Código de Mejores Prácticas Corporativas de 2010, se recomienda que el consejo gestione la sociedad en beneficio de sus accionistas, pero teniendo en cuenta las «opiniones» de los stakeholders. En lo que respecta a España ${ }^{90}$ el Código Unificado de Buen Gobierno, tampoco deja dudas en cuanto a su posición. El consejo deberá perseguir el interés social como interés común de los accionistas. Finalmente, y para cerrar este apartado con mejor sabor de boca, decir que en Brasil91, en su Código de Buenas Prácticas de septiembre de 2009 —en el apartado 2.2 dedicado a la misión del Consejo de Administración-, se determina que este deberá «ponderar los intereses de las steakholders (accionistas y otros stakeholders), para que cada uno reciba el beneficio apropiado y proporcional a su participación en la sociedad...» Pone en un plano de igualdad a todos los stakeholders. Claramente Stakeholder theory.

Del rápido repaso realizado, en países que además tienen un Código de Gobierno Corporativo bastante actualizado, podemos ver que el paisaje es realmente desolador. Es cierto que son códigos de voluntario cumplimiento, sometidos, únicamente al principio de «comply or explain», pero por eso mismo hubiera sido mucho más fácil el introducir una sesgo más próximo a la stakeholder theory. Ha sido imposible. De los 25 códigos analizados, excepto 4, todos los demás son decididamente pro accionistas en exclusiva.

\section{Conclusión}

Tanto la doctrina Norte Americana como la Británica admiten de forma mayoritaria la necesidad de proceder a una revisión en profundidad de cual a de ser el fin u objetivo de la sociedad. Además, tanto a través de los Constitiencies Statutes como del Enlightened Shareholder Value, existen los cimientos normativos para proceder a la aplicación de una visión mucho más cercana a los postulados de la Stakeholders Theory. El momento económico-político - tras la cleptocrisis financiera de los últimos años, así como de los escándalos retributivos destapados - es, asimismo, propicio. Pero sin embargo y paradójicamente, la

89 Ver en http://www.ecgi.org/codes/documents/codigo_de_mejores_practicas_ corporativas_2010_es.pdf. Última entrada, 15 de enero de 2013.

90 Ver en http://www.ecgi.org/codes/documents/unified_code_may2006_es.pdf. Última entrada, 15 de enero de 2013.

91 Ver en http://www.ecgi.org/codes/documents/ibcg_sep2009_en.pdf. Última entrada, 15 de enero de 2013. 
realidad nos dice que la implementación del citado modelo ha sido imposible de realizarse con éxito. ¿Qué ha fallado? Sólo existe una respuesta. La Stakeholder Theory, en su formulación actual, es deficiente.

Efectivamente así lo creemos. Tanto su falta de claridad, en lo que se refiere a la existencia de intereses distintos, para cada grupo de «interesados»; como la inexistencia de mecanismos procesales para exigir judicialmente - por parte de los distintos stakeholders - la aplicación de esta teoría, la hacen inaplicable. Por mucho que estemos más cerca - desde un punto de vista moral- de esta teoría, lo cierto es que es de justicia reconocer que la Shareholder Primacy, ofrece a los agentes sociales, un objetivo claro y exigible. En tanto en cuanto la doctrina no sea capaz de idear un sistema de evaluación y asignación de cuotas entre los distintos tipos de «interesados» de cada sociedad (lo cual vemos como una misión imposible), entendemos que será imposible la aplicación de esta teoría a una sociedad capitalista. Ante esta imposibilidad, y si queremos realmente una forma social justa, que mantenga el principio liberal constitutivo y de funcionamiento empresarial, solamente nos quedará acudir a la Sociedad Cooperativa.

\section{Bibliografía}

\section{Libros}

AA.VV.: "Compendio de la Doctrina Social de la Iglesia». Consejo Pontificio «Justicia y Paz». Ed: Biblioteca de Autores Cristianos. 2012.

Botтomley, S.: The Constitutional Corporation. Burlington Vermont, Ed: Ashgate Publishing Limited. USA. 2008.

Branson, D.: "The Death of Contractarianism and the Vindication of Structure and Authority in Corporate Governance and Corporate Law», en MITCHELL, L.: Progressive Corporate Law. Boulder, Ed: Westview Press, 1995.

ChARNY, D.: "Competition among Jurisdictions in Formulating Corporate Law Rules; An American Perspective on the "Race to the Bottom", in European Communities», en Harvard International Law Journal, vol. 32 de 1991, p. 423. Romano, R.: "The genious of American Corporate Law». Ed. AEI Press. Washington, U.S.A. 1993.

Clark, R.: Corporate Law. Chicago. Ed:Aspen Publishers. 1986.

COASE, R.: The nature of the firm. Chicago. Ed: The University of Chicago Press. 1937.

Greenfield, K.: The failure of Corporate Law. Chicago. Ed: The University of Chicago Press. 2006.

Hopt, K.J.: Estudios de Derecho de Sociedades y del Mercado de Valores. Madrid. Ed. Marcial Pons. 2010. 
KeAY, A.: The Corporate Objetive. Chentelham. Ed: Edward Elgar Publishing Limited. U.K. 2011.

KEAY, A.: The Enlightened Shareholder Value Principle and Corporate Governance. New York. Ed: Routledge. 2.013.

KraAkman, R. et al.: The Anatomy of Corporate Law. A comparative and functional approach, 2. ${ }^{a}$ edición. Oxford. Oxford University Press. 2009.

MACEY, J.: «Fiduciary duties as Residual Claims: Obligations to Nonshareholder Constituencies from a theory from the firm Perspective», en Cornell Law Review, vol. 84 de 1999. KeaY, A.: The Enligted Shareholder Value Principle and Corporate Governance. New York Ed: Routledge. 2013.

Plender, J.: «A Stake in the Future: The Stakeholder Solution». Ed: Nicolas Bradley Publishing. London. 1997, en KeAY, A.: The Corporate Objetive. Chentelham. Ed: Edward Elgar Publishing Limited.U.K. 2011.

Romano, R.: The genious of American Corporate Law. Washington, U.S.A. Ed. AEI Press. 1993.

Stout, L.: The Shareholder Value Myth. San Francisco. Ed:Berrett-Koehler Publishers Inc. 2012.

TELES, S.: The rise of the conservative legal movement: The battle for control of the law. Princetown. Princetown University Press. 2008.

\section{Revistas}

Adams, E. y Matheson, J.: «A Statutary Model for Corporate Constituency Concerns», en Emory Law Journal, vol. 49 de 2000.

ARMOUR, J. y WhINCOP, M.: "The property foundations of Corporate Law», en Oxford Journal of legal Society, vol. 27 de 2007.

BAINBRIDGE, S.: «Interpreting Nonshareholders Constituency Statutes», en Pepperdine Law Review, vol. 19 de 1992.

BIscontI, A.: «The double Bottom Line: Can Constituency Statutes Protect Socially responsables Corporations Stuck in Revlon Land?», en Loyola Los Ángeles Law review, vol. 42, de 2009.

BLACK, B. y KRAACKMAN, R.: "A self-enforcing Model of Corporate Law», en Harvard Law Review, vol. 109 de 1996.

BLAIR, M. y Stout, L.: «A Tean Production Theory of Corporate Law», en Virginia Law Review, vol. 85 de 1999.

BRATTON, W.W. y WATCHER, M.L.: "Adolf Berle and the Modern Corporation», en The Journal of Corporate Law, vol. 34 de 2008.

BUTLER, H.N. y MCCHESNEY, F.S.: "Why they give at the office: shareholder Welfare and Corporate Philantrophy in the contractual Theory of the Corporation», en Cornell Law review, vol. 84 de 1999.

CLARKSON, M.: «A Stakeholder framework for Analizing and Evaluating Corporate Social Performance», en Academy Management Review, vol. 20 de 1995.

COUWENBERG, O.: «Corporated Arquitecture and Limited Liability», en Review of Law and Economics, vol. 4. 2008. 
DodD, E.M.: «For Whom are Corporate Managers Trustees?», en Harvard Law Review», vol. 45 de 1932.

EASTERBROOK, F. y FISHEL, D.: «The Corporate Contract», en Columbia Law Review, vol. 89 de 1989.

Elhauge, E.: "Sacrifiing Corporate Profits in the Public Interest», en New York University Law Review, vol. 80 de 2005, p. 733; LeE, I.B.: «Efficiency and Ethics in the debate about Shareholder Primacy», en Delaware Journal of Corporate Law, vol. 31 de 2006.

FASsIM, Y.: «The Stakeholder Model Refined», en Journal of Business Ethics, vol. 84 de 2009, p. 113.

FreEmAn EdWARD: Strategic Management: a Stakeholder Approach. Ed: pitman/ Ballinger. Boston. 1.984.

FreEMAN, R.E. y PhilliPS, R.: "Stakeholder Theory: A Libertarian Defense», en Business Ethics Quarterly, vol. 12 de 2002.

GiBson, K.: «The moral basis of Stokeholder Theory», en Journal of Business Ethics, vol. 26 de 2000.

GREeNFIELD, K.: «Saving the world with Corporate Law», en Emory Law Journal, vol. 57 (2008).

Grossman, S. and HART, O.: "The Cost and Benefits of Ownership: A Theory of Vertical and Lateral Integration», en Journal of Political Economy, vol. 94 de 1986.

Hu, H.: «Risk, Time and Fiduciary Principles in Corporate Investment», en University of California at Los Ángeles Law Review, vol. 38. 1990.

JenSEN, M. y MECKLING, W.: "Theory of the firm: Managerial behavior, Agency Costs and Ownership Structure», en Journal of Financial Economics, vol. 3, N4. October, 1976.

Jensen, M.: «Value Maximisation, Stakeholder Theory, and the Corporate Objetice Function», en European Financial Management, vol. 7, de 2001.

KeAY, A.: "Shareholder Primacy in Corporate Law: Can it Survive?», en European Company and Financial Law Review, vol. 7, 2010.

LEARMOUNT, S.: «Theorizing Corporate Governance: New Organizational Alternatives», en Journal of Interdisciplinary Economics, vol. 14 de 2003.

LEE, I.: "Efficiency and Ethics in the Debate About Shareholder Primacy», en Delaware Journal of Corporate Law, vol. 31 de 2006.

LEUNG, W.: "The Inadecuancy of Shareholder Primacy: A Proposed Corporate Regime That Recognizes Non-Shareholder Interest», en Columbia Journal of Law and Social problems, vol. 30 de 1997.

MACEY, J.: «Fiduciary Duties as Residual Claims: Obligations to nonshareholders Constituencies From a Theory of the Firm Perspective», en Cornell Law review, vol. 84 de 1999.

MILLON, D.: «New Directions in Corporate Law: Communitarians, Contractarians and Crisis in Corporate Law», en Washigton and Lee Law Review, vol. 50 de 1993.

MıLLON, D.: "Why is Corporate Management obsessed With Quarterly Earnings and What Should be Done about it?», en George Washigton Law Review, vol. 70 de 2002. 
OMran, M.; AtRILL, P. y PrESTON, L.: «Shareholders versus Stakeholders: corporate mision statements and investors Returns», en Business Ethics: a European Review, vol. 11 de 2002.

OsWALD, L.: "Shareholders v Stakeholders: Evaluating Constituency Statutes under the Takings Clause», en Journal of Corporation Law, vol. 23 de 1997.

PHILlIPS, R.: "Stakeholder Legitimacy», en Business Ethics Quarterly, vol 13 de 2003.

Rотн, M.: «Employee participation, Corporate Governance and the firm: A Transatlantic View Focused on Occupational Pensions and Co-determination», en European Business Organization Law Review, vol. 11 de 2010.

StoneY, C. y WinstanleY, D.: "Stakeholder Confusion or Utopia? Mappinig the Conceptual Terrain», en Journal of Management Studies, vol. 38 de 2001.

WILIAMSON, O.: "The Vertical Integration of market production: Market Failure Considerations», en American Economic Review, vol. 61 de 1971.

Wood, D.: «Whom should Business serve?», en Australian Journal of Corporate Law, vol. 14, 2002.

\section{Instituciones y organismos}

Institute for Policy Studies. Estudio realizado por AnDERSON, S. y CAVANAGH, J. Disponible en http://www.ips-dc.org/downloads/Top_200.pdf. Última entrada, 20 de enero de 2013.

\section{Publicaciones en internet}

Relacionamos link de acceso a los Códigos de Buen Gobierno de Sociedades Cotizadas, disponibles en la página web del European Corporate Governance Institute.

Alemania, http://www.ecgi.org/codes/documents/cg_code_germany_ 15may2012_en.pdf. Última entrada, 15 de enero de 2013.

Arabia Saudí, http://www.ecgi.org/codes/documents/cg_regulations_saudi_ arabia_16mar2012_en.pdf.

Australia, http://www.ecgi.org/codes/documents/cg_marked_up_amendments 30jun2010.pdf. Última entrada, 15 de enero de 2013.

Austria, http://www.ecgi.org/codes/documents/cg_code_austria_jan2012_ en.pdf. Última entrada, 15 de enero de 2013.

Bélgica, http://www.ecgi.org/codes/code.php?code_id=256. Última entrada, 15 de enero de 2013.

Brasil, http://www.ecgi.org/codes/documents/ibcg_sep2009_en.pdf. Última entrada, 15 de enero de 2013.

Canadá, http://www.ecgi.org/codes/documents/tsx_guide_to_good_disclosure. pdf. Última entrada, 15 de enero 2013. 
China, http://unpan1.un.org/intradoc/groups/public/documents/apcity/ unpan033862.pdf. Última entrada, 15 de enero de 2013.

Dinamarca, http://www.ecgi.org/codes/documents/cg_recommendations_ denmark_aug2011_en.pdf. Última entrada, 15 de enero de 2013.

EE.UU., http://www.ecgi.org/codes/documents/nyse_cgreport_23sep2010_ en.pdf. Última entrada, 15 de enero de 2013.

España, http://www.ecgi.org/codes/documents/unified_code_may2006_es.pdf. Última entrada, 15 de enero de 2013.

Finlandia, http://www.ecgi.org/codes/documents/finnish_cg_code_2010_ en.pdf. Última entrada, 15 de enero de 2013.

Francia, http://www.ecgi.org/codes/documents/cg_recommendations_afg_ 2011_en.pdf. Última entrada, 15 de enero de 2013

Holanda, http://www.ecgi.org/codes/documents/cg_code_netherlands_ dec2008_en.pdf. Última entrada, 15 de enero de 2013.

Italia, http://www.ecgi.org/codes/documents/codice_corpgov_2011_en.pdf. Última entrada, 15 de enero de 2013.

Japón, http://www.ecgi.org/codes/documents/principles_japan_dec2009_ en.pdf. Última entrada, 15 de enero de 2013.

Méjico, http://www.ecgi.org/codes/documents/codigo_de_mejores_practicas_ corporativas_2010_es.pdf. Última entrada, 15 de enero de 2013.

Noruega, http://www.ecgi.org/codes/documents/code_of_practice_norway_ 23oct2012_en.pdf. Última entrada, de 2013.

OCDE, http://Www.ecgi.org/codes/documents/principles_en_final.pdf. Última entrada, 15 de enero de 2013.

Portugal, http://www.ecgi.org/codes/documents/cmvm_cg_recommendations 2010_en.pdf. Última entrada, 15 de enero de 2013.

Reino Unido, http://www.ecgi.org/codes/documents/cg_code_uk_sep2012_ en.pdf. Última entrada, 15 de enero de 2013.

Rusia, http://www.ecgi.org/codes/documents/final_code_english.pdf. Última entrada, 15 de enero de 2013.

Singapur, http://www.ecgi.org/codes/documents/cg_code_singapore_ 2may2012_en.pdf. Última entrada, 15 de enero de 2013.

Suecia, http://www.ecgi.org/codes/documents/cg_code_sweden_feb2010_ en.pdf. Última entrada, 15 de enero de 2013.

Suiza, http://www.ecgi.org/codes/documents/swiss_code_feb2008_en.pdf. Última entrada, 15 de enero de 2013.

FISCH, J.: «Measuring Efficiency in Corporate Law: The Rule of Shareholder Primacy». December 2005, Fordham Law Legal Studies, Working Paper n. ${ }^{\circ} 105$, p. 29, en http://ssrn.com/abstract=878391. Última entrada, 15 de junio de 2012.

Loderer, J. et al.: "Shareholder Value: Principles, Declarations and Actions». April 22, 2009. European Corporate Institute Working Paper No 95/2006. Ver en http://papers.ssrn.com/sol3/papers.cfm?abstract_id=690044. Última entrada, 17 de enero de 2013. 